DOI https://doi.org/10.33314/jnhrc.1475

\title{
Study on Serum Vitamin D in Alopecia Areata Patients
}

\author{
Suchana Marahatta, ${ }^{1}$ Sudha Agrawal, ${ }^{1}$ Seraj Khan ${ }^{2}$ \\ ${ }^{1}$ Department of Dermatology, ${ }^{2}$ Department of Biochemistry, B.P. Koirala Institute of Health Sciences, Dharan, \\ Nepal
}

\section{ABSTRACT}

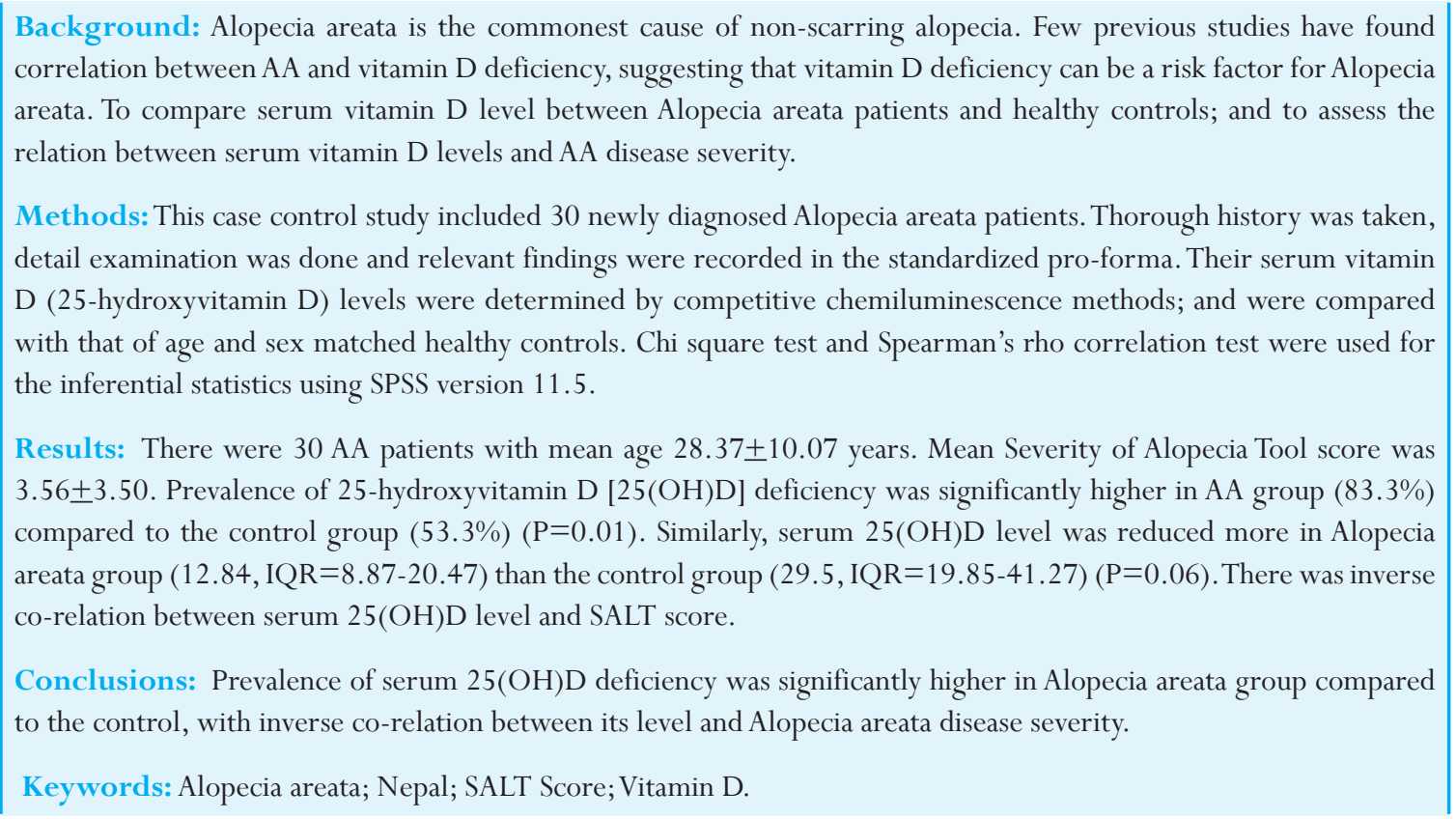

\section{INTRODUCTION}

Alopecia areata (AA) is the most common cause of nonscarring hair loss. It's frequency ranges from $0.7 \%$ to $3.8 \%$ of patients attending dermatology clinics with a lifetime risk of $1.7 \% .^{1-3}$

It has been demonstrated that vitamin D receptor (VDR) is strongly expressed in the key structure of human hair follicles; ${ }^{4}$ and expression of VDRs in keratinocytes is necessary for the maintenance of the normal hair cycle. ${ }^{5}$ Deficient or reduced VDRs decrease growth of hair follicle. ${ }^{6}$

The available studies till date had shown inconsistent results as some had found strong correlation, whereas others did not find any correlation between $A A$ and serum vitamin D level. ${ }^{7-10}$ Hence we conducted this study in Nepal to assess the serum vitamin D level in patients with $A A$ and to study the correlation between serum vitamin $D$ level and AA disease severity.

\section{METHODS}

This hospital based case-control study included 30 consecutive AA patients attending dermatology outpatient department of BPKIHS, Dharan, Nepal over a year period (from October 2015 to September 2016). However subjects not willing to participate in the study, known case of chronic renal or liver disease, pregnant or lactating, any subject treated with a topical, intralesional or systemic agent in the past month which is likely to cause hair re-growth were excluded from the study.

All patients were diagnosed clinically by the consultant dermatologist of the department. However, there was doubt on clinical diagnosis in three patients. Hence they

Correspondence: Suchana Marahatta, Department of Dermatology and Venereology, B. P. Koirala Institute of Health Sciences (BPKIHS), Dharan, Nepal. Email: suchanamarahatta@yahoo.com, Phone: +9779862023236. 
were subjected for the skin biopsy and histopathology for the diagnosis. Particulars of patients, relevant history and examination findings were recorded in the preset pro-forma. The severity of AA was graded according to Kavak et al, 2000 into: mild, moderate, severe, and snake shaped plaques extending to the scalp border or loss of hair in the shape of a wave at the circumference of head defined as ophiasis. ${ }^{11}$ Likewise, global AA Severity Score which is also called Severity of Alopecia Tool (SALT) score was also used for the calculation of severity as proposed by Olsen et al, 2004. ${ }^{12}$ All patients were treated according to standard treatment protocol for AA.

Although 1,25-dihydroxyvitamin $D \quad[1,25(\mathrm{OH}) 2 \mathrm{D} 3]$ is the biologically active form of vitamin $D$, it has a halflife of less than 4 hour and the levels can sometimes remain normal in vitamin $D$ deficiency. Therefore 25-hydroxyvitamin D [25(OH)D], which has a half-life of about 2 weeks, is routinely assessed. ${ }^{13}$

The serum concentration of $25(\mathrm{OH}) \mathrm{D}$ was assessed in each AA patient on the day of enrollment using competitive chemiluminescence methods and their $25(\mathrm{OH}) \mathrm{D}$ level was compared with that of age and sex matched healthy controls from hospital staffs. The vitamin $D$ deficiency was defined as serum concentration of vitamin $D$ as $\leq 20$ $\mathrm{ng} / \mathrm{ml}$.

Ethical clearance was obtained from Institutional Review Committee (IRC) of BPKIHS with IRC no: 492/015

After data collection, all the data were entered in the Microsoft excel sheet and were converted to SPSS version 11.5 for the analysis. For descriptive statistics $\%$, proportion, mean, median, standard deviation, inter quartile range were calculated. For inferential statistics: Chi square test and Spearman's rho correlation test were calculated at $95 \%$ Confidence Interval $(\mathrm{Cl})$ and $\mathrm{p}=0.05$.

\section{RESULTS}

A total of 30 AA patients and 30 age and sex matched healthy individuals were evaluated over a year period. The mean age of case and control group was $28.37 \pm 10.07$ and $30.50 \pm 9.03$ year respectively (table 2 ). More than half of the AA patients (56.7\%) were of 20-40 years. Most of them (56.7\%) had completed school level education.

Mean age during the onset of first lesion was $26.10 \pm 10.57$ year. Mean number of hair loss episodes were 1.67+1.09. Median no of lesion was 2 (IQR: 1.00-4.25). More than half $(56.7 \%)$ had gradual progression of disease. One third patients $(36.7 \%)$ had recurrent episodes of $\mathrm{AA}$ (table 1).

\begin{tabular}{|c|c|c|}
\hline Characteristics & Category & $\begin{array}{l}\text { Number of } \\
\text { Patient (\%) }\end{array}$ \\
\hline \multirow{2}{*}{$\begin{array}{l}\text { Progression of } \\
\text { lesion }\end{array}$} & Gradual & $17(56.7)$ \\
\hline & Rapid & $13(43.3)$ \\
\hline \multirow[t]{2}{*}{ No of episodes } & First episode & $19(63.3)$ \\
\hline & Recurrent episodes & $11(36.7)$ \\
\hline \multirow{2}{*}{$\begin{array}{l}\text { Sites affected by } \\
\text { AA }\end{array}$} & Scalp & $29(96.7)$ \\
\hline & Face & $8(26.6)$ \\
\hline
\end{tabular}

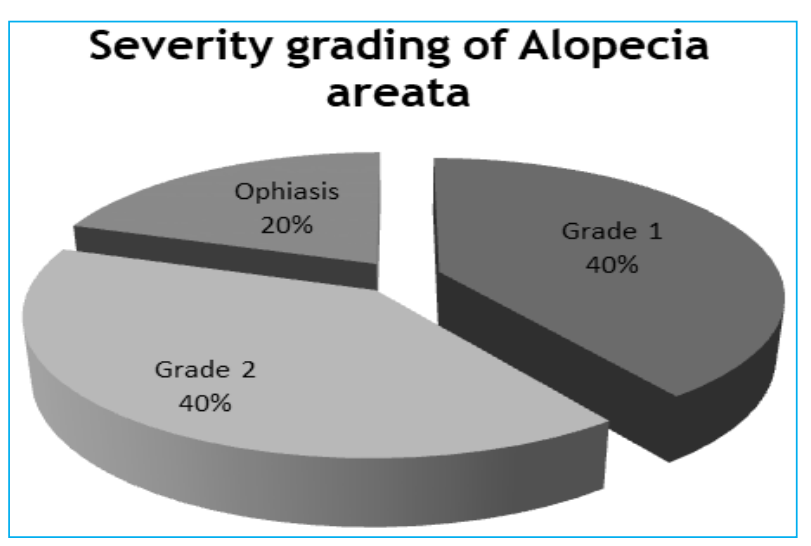

Figure 1: Severity of AA.

SALT score: Mean SALT score of the patient was: $3.56+3.50$.

Serum Vitamin D was deficient in both case and control group. But, the deficiency was significantly more in AA group $(83.3 \%)$ compared to the control group (53.3\%) $(p=0.01)$.

Comparison between case and control groups: Case and control groups were comparable both for age and sex (Table: 2).

Table 2. Demographic and laboratory data of case and control group.

\begin{tabular}{|c|c|c|c|}
\hline Category & $\begin{array}{l}\text { AA group } \\
(n=30)\end{array}$ & $\begin{array}{c}\text { Control } \\
\text { group } \\
(n=30)\end{array}$ & $\begin{array}{r}P \\
\text { value }\end{array}$ \\
\hline Age (years) & $28.37 \pm 10.070$ & $30.50 \pm 9.032$ & 0.39 \\
\hline \multicolumn{4}{|l|}{ Gender, n(\%) } \\
\hline Male & $16(51.6 \%)$ & $15(48.4 \%)$ & 0.79 \\
\hline Female & 14 (48.3\%) & 15 (51.7\%) & \\
\hline $\begin{array}{l}\text { Serum vitamin D } \\
(\mathrm{ng} / \mathrm{ml})\end{array}$ & $21.22 \pm 25.44$ & $30.90 \pm 11.13$ & 0.06 \\
\hline $\begin{array}{l}\text { Serum vitamin } \\
D, \text { median }(I Q R)\end{array}$ & $\begin{array}{r}12.84(8.87- \\
20.47)\end{array}$ & $\begin{array}{r}29.5(19.85- \\
41.27)\end{array}$ & \\
\hline $\begin{array}{l}\text { Vitamin } \mathrm{D} \\
\text { deficiency, } \mathrm{n}(\%)\end{array}$ & 25 (83.3\%) & $16(53.3 \%)$ & 0.01 \\
\hline
\end{tabular}


The patients with more severe type of AA (both by SALT score and AA grading system) tend to have lower serum vitamin $D$ and vice-versa, as there was inverse co-relation between serum vitamin D level and SALT score $(r=-.026$, $\mathrm{P}=0.89)$; and $\mathrm{AA}$ grade $(\mathrm{r}=-.102, \mathrm{P}=0.59)$. However, they were statistically not significant (Table 3 ).

\section{Table 3. Co-relation between AA and severity.}

\begin{tabular}{|c|c|c|}
\hline Category & Serum vitamin D & (Spearman's \\
\hline SALT score $(n=29)$ & $r=-.026, P=0.89$ & \\
\hline AA grade $(n=30)$ & $r=-.102, P=0.59$ & $\begin{array}{l}\text { correlation } \\
\text { test) }\end{array}$ \\
\hline
\end{tabular}

\section{DISCUSSION}

Since the enzymatic process for conversion of inactive to active form of vitamin $D$ as well as vitamin $D$ receptors are present in many cells of the body, it plays an important role in array of diseases. Though it is thought that vitamin D might play an important role in many autoimmune diseases like alopecia areata, vitiligo, systemic lupus erythematosus, rheumatoid arthritis, autoimmune thyroid disorder, anemia etc; it is still inconclusive and needs further more evidence on this matter. ${ }^{14} \mathrm{~A}$ pilot study has reported that very low serum vitamin $D$ level was strongly associated with autoimmune diseases in vitiligo patients $(\mathrm{OR}=10.00,95 \% \mathrm{Cl}=1.06$ 94.7). ${ }^{15}$ However, Karagun $\mathrm{E}$ et al, did not find significant difference between serum vitamin $D$ level of vitiligo patients and control groups. ${ }^{16}$ Similarly, according to a meta-analysis, individuals with autoimmune thyroid disease were more likely to have vitamin D deficiency as compared to the controls. ${ }^{17}$ But, a recent RCT did not supported the role of vitamin D on thyroid autoimmunity; because vitamin $\mathrm{D}$ supplementation did not reduced thyroid autoantibody level in this study. ${ }^{18}$ Hence, there are still many controversies on this topic. Moreover, we still need to work a lot to know whether low serum vitamin $\mathrm{D}$ possess risk of autoimmunity or autoimmune processes predispose vitamin D deficiency. Hence to give a small input in this darker horizon, we tried to study serum vitamin D level in AA in a referral hospital of eastern Nepal.

In this study, we evaluated total of 30 AA patients and assessed their serum vitamin D (25-Hydroxyvitamin D (25(OH)-D)) level over a year period. Then, we compared the level of serum vitamin D of AA patients with that of age and sex matched healthy controls. Mean age of case and control groups were comparable $(28.37 \pm 10.070 \&$ $30.50 \pm 9.032$ respectively), number of male and female were also comparable between case and control group. Most of the patients had ( $40 \%$ each) grade 1 and grade
2 AA. Mean SALT score of the patient was: $3.56 \pm 3.50$. There was significant difference between the median serum vitamin D level in case (12.84, IQR: 8.87-20.47) and control (29.5, IQR: 19.85-41.27) group $(\mathrm{p}=0.06)$. There was significantly high prevalence of vitamin $D$ deficiency in AA group (83.3\%) compared to the control group $(53.3 \%)(p=0.01)$.

In a study by Wasserman et al, scalp was the most commonly affected site (in $>90 \%$ cases). Similar to this study, in our study, $96.7 \%$ patients had involvement of scalp and $26.6 \%$ had involvement of facial hair. ${ }^{19}$

In a study done by Mahamid et al, in Israel, Vitamin D levels were significantly decreased in the AA group as compared with the control group $(11.32 \pm 10.18$ vs. $21.55 \pm 13.62 \mathrm{ng} / \mathrm{ml}, \mathrm{P}<0.05) ; 16$ patients in the AA group $(69.5 \%)$ versus only 5 patients $(25 \%)$ in the control group had low vitamin D levels. ${ }^{9}$ Likewise, in our study also there was marked difference between median serum vitamin $D$ level in case $(12.84 \mathrm{ng} / \mathrm{ml}$, IQR: 8.87 20.47) and control (29.5 ng/ml, IQR: 19.85-41.27) group $(p=0.06)$. Similarly, in our study also prevalence of vitamin $D$ deficiency in AA group (83.3\%) was very high compared to the control group $(53.3 \%) \quad(p=0.01)$. In contrast, prevalence of vitamin $D$ deficiency in our control group is very high $(53.3 \%)$, which is more than double in our study compared to the study of Mahamid et al,. ${ }^{9}$

Similarly in another study by Cerman et al, the prevalence of $25(\mathrm{OH}) \mathrm{D}$ deficiency was significantly higher in patients with AA (91\%) compared with patients with vitiligo (71\%) and healthy controls (33\%). ${ }^{7}$ In our study also vitamin $D$ deficiency in AA group was comparable to this study. However, control group were more deficient in vitamin $D$ in our study.

A significant negative correlation between SALT score and serum 25(OH)D level was found in the patients with $\mathrm{AA}$ in a previous study. ${ }^{7}$ Likewise, we also found negative correlation between serum vitamin D level \& SALT score $(\mathrm{r}=-0.026, \mathrm{P}=0.89)$ as well as serum vitamin $\mathrm{D}$ level $\&$ AA grade $(r=-0.102, P=0.59)$. However, they were not significant statistically. A recent study from India also reported that vitamin $D$ deficiency was significantly higher in $\mathrm{AA}$ patients (96.7\%) then in controls (73.3\%). Likewise, similar to our study, they also found an inverse correlation between serum vitamin D level and SALT score $(r=-0.256, p=0.17) .^{20}$

Yilmaz et al, found that AA patients (85\%) had significant deficiency of $25(\mathrm{OH})-\mathrm{D}, 1,25(\mathrm{OH}) 2 \mathrm{D} 3$ concentrations in comparison to control $(33 \%) .{ }^{10}$ However in contrast to 
our study, there was no correlation between extent of the hair loss patch and number of patches in this study.

Vitamin D deficiency is more prevalent (i.e. 6-70\%) in south-east Asia than expected. As stated by different studies, prevalence of vitamin D deficiency is $50-94 \%$ in India, 69\% in China, 47-65\% in South Korea and 6\% in Thailand. ${ }^{21-24}$ Similar to these studies; prevalence of vitamin $D$ deficiency was high even in our study. But, if we see the geography of Nepal, vitamin D deficiency must not be an issue in Nepalese population. Nepal is situated at $28^{\circ} \mathrm{N}$ and almost half of the land area in the Southern Nepal is in the tropical zone with maximum sunny days all year round. Likewise, significant area of Northern Nepal is composed of hills and mountains, with high altitudes. This also favors more vitamin $D$ synthesis because the path length of the UVB in the atmosphere is shorter in the high altitude. According to the evidence, pre-vitamin $D_{3}$ synthesis at the Mt Everest base camp $(5300 \mathrm{M})$ was 5 times higher than that of Agra (169 $M)$, both places with same latitude. ${ }^{25}$ Hence, all these geographical factors favor more vitamin $D$ synthesis in Nepalese population.

However, following factors may contribute for vitamin D deficiency in our country: 1) Our food items and dairy products are rarely fortified with vitamin D. 2) The socio-cultural practice of wearing fully covered clothing may limit the adequate vitamin D synthesis in Nepalese population. 2) Most of us have skin phototype 4 and 5, and the darker skin doesn't favor significant vitamin $\mathrm{D}$ production even on adequate sun exposure. Vitamin $D$ produced in the skin of phototype 2 is 30 times higher than that of phototype 5 on equal UVB radiation exposure. ${ }^{26}$ Similarly, according to Holick's rule i.e. exposing face, arms and legs for a period equal to $25 \%$ of the time which is needed to produce 1 minimum erythema dose (MED) for two to three times a week can suffice vitamin $D$ requirement of the body. The MED of darker skin is significantly higher than that of lighter ones; hence requiring longer sun exposure. ${ }^{27} 3$ ) Because of pigmentation prone skin, many of us might be using sunscreen. It has been found that a sunscreen with a sun protection factor (SPF)-15 absorbs $99 \%$ of the incident UVB radiation; thus decreasing the synthesis of vitamin D3 by $99 \%$ after appropriate topical application. ${ }^{28} 4$ ) Similarly, increasing trend of indoor lifestyle, pollution, unspaced and unplanned pregnancies may also be minor contributors for this. ${ }^{21,29}$

So, these could be few of the explanations, for vitamin $D$ deficiency in Nepalese population. But, despite all these factors, vitamin $D$ deficiency is significantly more in $A A$ group as compared to the control group.

Hours of sun exposure, sunscreen using habits and dietary habits could not be matched between case and control group. Since the control group included age and sex matched hospital staffs, they might have less outdoor activities and more sunscreen using habits. So, there might be some selection bias among the controls.

\section{CONCLUSIONS}

We found significantly higher prevalence of serum vitamin $D$ deficiency in $\mathrm{AA}$ patients compared to the control group. We also find an inverse co-relation between its level and AA disease severity grading, but it was not significant. Hence, we can propose that there is a role of vitamin $D$ in the pathogenesis of AA. However, further multi-center studies with larger sample size are recommended for stronger evidence. Another important finding of the study was significantly higher prevalence of vitamin $D$ deficiency even in healthy Nepalese controls. So, we would like to draw attention of higher authorities and stakeholders to work seriously on nutritional deficiency of the population.

\section{REFERENCES}

1. Sharma VK, Dawn G, Kumar B. Profile of alopecia areata in Northern India. International journal of dermatology. 1996 Jan;35(1):22-7.[DOI]

2. Tan E, Tay YK, Goh CL, Chin Giam Y. The pattern and profile of alopecia areata in Singapore-a study of 219 Asians. International journal of dermatology. 2002 Nov;41(11):748-53.[DOI]

3. Safavi KH, Muller SA, Suman VJ, Moshell AN, Melton III LJ. Incidence of alopecia areata in Olmsted County, Minnesota, 1975 through 1989. InMayo Clinic Proceedings 1995 Jul 1 (Vol. 70, No. 7, pp. 628-633). Elsevier. Science Direct]

4. Boucher BJ. Curcumin and diabetes: a role for the vitamin D receptor?. British Journal of Nutrition. 2012 Dec;108(11):2104-.[DOI]

5. Bikle DD. Vitamin D metabolism and function in the skin. Mol Cell Endocrinol 2011; 347:80-9.

6. Mulloy PJ, Feldman D. The role of vitamin D receptor mutations in the development of alopecia. Mol Cell Endocrinol 2011;347:90-6.

7. Aksu Cerman A, Sarikaya Solak S, Kivanc Altunay I. Vitamin D deficiency in alopecia areata. British Journal of Dermatology. 2014 Jun;170(6):1299-304.[DOI] 
8. D'Ovidio R, Vessio M, d'Ovidio FD. Reduced level of 25-hydroxyvitamin D in chronic/relapsing alopecia areata. Dermato-endocrinology. 2013 Apr 1;5(2):271-3.[DOI]

9. Mahamid M, Abu-Elhija O, Samamra M, Mahamid A, Nseir W. Association between vitamin D levels and alopecia areata. The Israel Medical Association journal: IMAJ. 2014 Jun;16(6):367-70.[Link]

10. Yilmaz N, Serarslan G, Gokce C.Vitamin D Concentrations are Decreased in Patients with Alopecia Areata.Vitam Trace Elem 2012;1:105. doi:10.4172/2167-0390.1000105.

11. Kavak A, Baykal C, Özarmağan G, Akar U. HLA in alopecia areata. International journal of dermatology. 2000 Aug;39(8):589-92.[DOI]

12. Olsen EA, Hordinsky MK, Price VH, Roberts JL, Shapiro J, Canfield D, Duvic M, King LE, McMichael AJ, Randall VA, Turner ML. Alopecia areata investigational assessment guidelines-Part II. Journal of the American Academy of Dermatology. 2004 Sep 1;51(3):440-7.[Link]

13. Saleh HM, Abdel Fattah NS, Hamza HT. Evaluation of serum 25-hydroxyvitamin D levels in vitiligo patients with and without autoimmune diseases. Photodermatology, photoimmunology \& photomedicine. 2013 Feb;29(1):3440.[DOI]

14. Wadhwa B, Relhan V, Goel K, Kochhar AM, Garg VK. Vitamin D and skin diseases: A review. Indian Journal of Dermatology, Venereology, and Leprology. 2015 Jul 1;81(4):344.[Full Text]

15. Silverberg JI, Silverberg AI, Malka E, Silverberg NB. A pilot study assessing the role of 25 hydroxy vitamin D levels in patients with vitiligo vulgaris. Journal of the American Academy of Dermatology. 2010 Jun 1;62(6):937-41. [Science Direct]

16. Karagün E, Ergin C, Baysak S, Erden G, AktaȘ H, Ekiz Ö. The role of serum vitamin D levels in vitiligo. Advances in Dermatology and Allergology/Postępy Dermatologii i Alergologii. 2016 Aug;33(4):300.[PubMed]

17. Wang J, Lv S, Chen G, Gao C, He J, Zhong H, Xu Y. Meta-analysis of the association between vitamin D and autoimmune thyroid disease. Nutrients. 2015 Apr 3;7(4):2485-98.[DOI]

18. Knutsen KV, Madar AA, Brekke M, Meyer HE, Eggemoen ÅR, Mdala I, Lagerløv P. Effect of Vitamin D on Thyroid Autoimmunity: A Randomized, Double-Blind, Controlled Trial Among Ethnic Minorities. Journal of the Endocrine Society. 2017 Apr 11;1(5):470-9.[DOI]

19. Wasserman D, Guzman-Sanchez DA, Scott K, McMichael A. Alopecia areata. International journal of dermatology. 2007 Feb;46(2):121-31.[DOI]
20. Gade VK, Mony A, Munisamy M, Chandrashekar L, Rajappa M. An investigation of vitamin D status in alopecia areata. Clinical and experimental medicine. 2018 Jun 4:18. [Link]

21. Aparna P, Muthathal S, Nongkynrih B, Gupta SK. Vitamin D deficiency in India. J Family Med Prim Care 2018;7:32430

22. Lu L, Yu Z, Pan A, Hu FB, Franco OH, Li H, Li X, Yang X, ChenY, Lin X. Plasma 25-hydroxyvitamin D concentration and metabolic syndrome among middle-aged and elderly Chinese individuals. Diabetes care. 2009 Jul 1;32(7):127883[DOI].

23. Choi HS, Oh HJ, Choi H, Choi WH, Kim JG, Kim KM, Kim KJ, Rhee Y, Lim SK. Vitamin D insufficiency in Korea - a greater threat to younger generation: the Korea National Health and Nutrition Examination Survey (KNHANES) 2008. The Journal of Clinical Endocrinology \& Metabolism. 2011 Mar 1;96(3):643-51.[DOI]

24. Chailurkit LO, Aekplakorn W, Ongphiphadhanakul B. Regional variation and determinants of vitamin D status in sunshine-abundant Thailand. BMC public health. 2011 Dec;11(1):853.[DOI]

25. Holick MF, Chen TC, Lu Z, Sauter E. Vitamin D and skin physiology: AD-lightful story. Journal of Bone and Mineral Research. 2007 Dec;22(S2):V28-33.[DOI]

26. Clemens TL, Henderson SL, Adams JS, Holick MF. Increased skin pigment reduces the capacity of skin to synthesise vitamin D3. The Lancet. 1982 Jan 9;319(8263):74-6.[DOI]

27. Holick MF. Vitamin D: importance in the prevention of cancers, type 1 diabetes, heart disease, and osteoporosis. The American journal of clinical nutrition. 2004 Mar 1;79(3):362-71.[DOI]

28. Holick MF. Vitamin D deficiency. N Engl J Med 2007; 357:266-81; [DOI]

29. Babu US, Calvo MS. Modern India and the vitamin D dilemma: evidence for the need of a national food fortification program. Molecular nutrition \& food research. 2010 Aug;54(8):1134-47.[DOI] 